\title{
The Impact of Neurofeedback on Clinical Signs of Children That Have Attention Deficit Disorder and Hyperactivity
}

\author{
Samaneh Hedayati Manesh ${ }^{1} \&$ Azam Alikhademi $^{2}$ \\ ${ }^{1}$ Department of Psychology, Islamic Azad University of Roudehen, Tehran, Iran \\ ${ }^{2}$ Faculty of Foreign language in Central Tehran Branch, Islamic Azad University, Tehran, Iran \\ Correspondence: Azam Alikhademi, Faculty of Foreign language in Central Tehran Branch, Islamic Azad \\ University, Tehran, Iran. E-mail: a_alikhademi@yahoo.com
}

Received: December 26, 2016

Accepted: February 6, 2017

Online Published: March 9, 2017

doi:10.5539/ijps.v9n2p48

URL: http://doi.org/10.5539/ijps.v9n2p48

\begin{abstract}
This study was an attempt to examine the impact of Neurofeedback on clinical signs of Children that have attention deficit disorder and hyperactivity. The participants of this study 24 boys (6-11) that afflicted to ADHD. The participants of the study randomly divided into two groups and were selected to participate in the study. The experimental group received the Neurofeedback treatment (8 weeks, three sessions in a week). The control group, on the other hand was placed in a wait list. After treatment, CBCL, IVA, QEEG were administered between two groups. The analysis of data revealed that Nero feedback has a significant impact on ADHD children. Moreover, Neurofeedback treatment leads to improve attention deficit disorder and decrease impulsivity in ADHD children.
\end{abstract}

Keywords: ADHD and attention deficit disorder, Neurofeedback

\section{Introduction}

Attention deficit and hyperactivity (ADHD) is a stable pattern of attention deficit and arousal that is more common and severe than normal children. There are some symptoms before the age of seven and lead to the clinical disorder in social, educational and professional functions of a person (American Psychiatric Association, 2000). ADHD is one of the most common psychiatric disorders between children and adolescents. Its prevalence is 3 to 7 and the proportion of boys to girls 4 to 1 (Cormirer, 2008). Most of the time, the parents of these children resort to some ways in order to control their behavior but it embitters their conditions (Fabiano et al., 2008). Nowadays, ADHD is a behavioral detection.

"Neurofeedback is a type of biofeedback that measures brain waves to produce a signal that can be used as feedback to teach self-regulation of brain function. Neurofeedback is commonly provided using video or sound, with positive feedback for desired brain activity and negative feedback for brain activity that is undesirable Related technologies include hem encephalography biofeedback (HEG) and functional magnetic resonance imaging (fMRI) biofeedback" (Margo, 2016).

The researchers examined different treatments in order to cure this behavior including Quantitative Electro Encephalography (QEEG) (Lazzaro, Gordon, \& Whitmont, 1998). Neurofeedback is also a safe, painless and non-invasive method in which an electrode called the sensor that is attached to the patient's head (Kaiser \& other, 2000). Frank H. Duffy, MD, a Professor and Pediatric Neurologist at Harvard Medical School, stated in an editorial in the January 2000 issue of the journal Clinical Electroencephalography that scholarly literature now suggests that Neurofeedback should play a major therapeutic role in many difficult areas (Duffy, 2002).

Hence the matter of this study is to examine the impact of Neurofeedback on clinical signs of Children that have attention deficit disorder and hyperactivity. One question is going to be addressed to what extent Nero feedback can be effective on clinical signs of children (6-11) that have attention deficit disorder and hyperactivity. The purpose of this study is to examine Nero feedback method and introduce advantage of it in improving and regulating brain waves. Moreover, it has long effects unlike medicine. 


\section{Methodology}

The present study sets out to investigate the effect of Neurofeedback on clinical signs of children that have attention deficit disorder and hyperactivity.

\subsection{Participant}

The Participants of the study were male who were selected from among a total number of 24 boys that were treated at the ATEYEH comprehensive psychiatric center in Tehran, Iran. They suffered from attention deficit disorder and hyperactivity. Control and experimental groups are the same as each other in pre-test and post-test of research.

\subsection{Instruments and Design}

In order to examine this study, the researchers applied various procedures such as, diagnostic interview, quantitative Elector Encephalography, Achenbach system of Empirically Based Assessment simultaneous test of visual and Audio Qualitative Electro Encephalography. It is equipment to record brain activities through electrode and Achenbach system of Empirically Based Assessment.

It consists of sheets in order to assess competency, Adaptive functioning and Emotional and behavioral problems simultaneous test of visual and audio: this test lasts 22 minutes in order to standardize the results and controlled by computer. The test can be divided into 4 parts: 1) warm up, 2) practice, 3) main CPT, 4) Calm down.

\subsection{Data Collection}

The researchers collected data and analyzed them through differenced steps as follows:

- 24 boys (6-11) were interviewed.

- To be assessed by QEEG.

- The boys answered the test (IVA) and CBCL regarding to the age, severity of disorder, and IQ.

- They are treated through Nero feedback in 8 weeks, there sessions (24 sessions). The duration of each session was 1 hour.

- Connected one electrode to the $c_{8}$ or $c_{4}$ for (SMR) and $c_{2}, f_{2}$ for (B). Two electrodes to the ears. EEG was also recorded in four bands TETA (4-8 H2), SMR (12-15), B (15-18H2) ß 2(19-28 H2).

\section{Data Analysis}

In order to the answer the question to what extent Neurofeedback can be effective on clinical signs of children (6-11) that have attention deficit disorder and hyperactivity. The results of this study shows the moderated averages have decreased in experimental group. As a result ADHD problems have decreased in experimental group. The following table shows moderated average between control and experimental groups.

Table 1. Moderated average between two groups

\begin{tabular}{llllll}
\hline Confidence interval & & $\begin{array}{l}\text { Standard } \\
\text { deviation }\end{array}$ & Average & Groups & Variable \\
\cline { 1 - 4 } High & Low & 0.361 & 9.592 & control & ADHD \\
\hline 10.344 & 8.839 & 0.361 & 6.075 & experimental & \\
6.827 & 5.329 & 0.463 & 9.893 & control & Attention \\
10.803 & 8.984 & 0.463 & 6.677 & experimental & deficit \\
7.683 & 5.864 & & & \\
\hline
\end{tabular}

The results of multivariable tests show that the pre-test scores have a significant and meaningful effect on the group $(\mathrm{P}<0.01)$. The Table two shows the results of multivariable covariance. 
Table 2. The results of multivariable tests

\begin{tabular}{llllllll}
\hline $\begin{array}{l}\text { ETA } \\
\text { separation }\end{array}$ & Meaningful & $\begin{array}{l}\text { The degree of } \\
\text { freedom deviation }\end{array}$ & $\begin{array}{l}\text { The degree of freedom } \\
\text { hypothesis }\end{array}$ & F & Rate & Tests & Agent \\
\hline 0.609 & 0.001 & 17 & 3.000 & 8.883 & 0.609 & PYLA \\
0.609 & 0.001 & 17 & 3.000 & 8.883 & 0.391 & LAMBDI & group \\
0.609 & 0.001 & 17 & 3.000 & & & VIIKEZ & Hetling \\
0.609 & 0.001 & 17 & 3.000 & 8.883 & 1.559 & 1.599 & The largest root \\
\hline
\end{tabular}

As can be seen in the Table 3, there is no statistically significant meaningful difference between two groups ( $\mathrm{P}>$ $0.05)$. On the other hand, the other factors statistically significant meaningful difference between two groups ( $\mathrm{P}$ $<0.05)$.

Table 3. Covariance analysis between two groups

\begin{tabular}{llllllll}
\hline $\begin{array}{l}\text { Square } \\
\text { Of ETA }\end{array}$ & Meaningful & F & $\begin{array}{l}\text { Square } \\
\text { average }\end{array}$ & $\begin{array}{l}\text { Freedom } \\
\text { degree }\end{array}$ & Sum of squares & Problem & $\begin{array}{l}\text { Variance } \\
\text { source }\end{array}$ \\
\hline $0 / 018$ & $0 / 565$ & $0 / 343$ & $6 / 101$ & 1 & 6.101 & hyperactivity & 'group \\
$0 / 544$ & $0 / 0001$ & $22 / 671$ & $27690 / 427$ & 1 & 27690.427 & attention & deviation \\
$0 / 487$ & $0 / 0001$ & $18 / 026$ & $17579 / 545$ & 1 & 17579.545 & impulsivity & hyperactivity \\
& & & $17 / 763$ & 19 & 337.492 & attention & impulsivity \\
& & & $1221 / 421$ & 19 & 23206.990 & & \\
& & & $975 / 220$ & 19 & 18529.180 & & \\
\hline
\end{tabular}

According to the Table 4, moderated average of variables between two groups indicates that moderated average is between $277 / 576$ and 321/208 in the experiment group except hyperactivity variable.

Table 4. Moderated average of variables between two groups

\begin{tabular}{|c|c|c|c|c|c|}
\hline \multicolumn{2}{|c|}{ Confidence interval } & \multirow{2}{*}{ Standard deviation } & \multirow{2}{*}{ Average } & \multirow{2}{*}{ Groups } & \multirow{2}{*}{ Variable } \\
\hline High & Low & & & & \\
\hline 111.135 & & 1.257 & 108.505 & control & hyperactivity \\
\hline 112.210 & & 1.257 & 109.79 & experimental & \\
\hline 248.841 & & 10.423 & 227.025 & control & attention \\
\hline 321.208 & & 10.423 & 299.392 & experimental & \\
\hline 317.830 & & 9.314 & 298.336 & control & impulsivity \\
\hline 375.491 & & 9.314 & 355.997 & experimental & \\
\hline
\end{tabular}

\section{Discussion}

The study was an attempt to examine the effect of Neurofeedback on clinical signs of children that have attention deficit disorder and hyperactivity. The findings of this study strongly and positively are the same as the previous studies like HILARD (2012), Peyerand et al. (2015), Vangler et al. (2011) and Gonslin (2010). The previous study shows that can be pointed out theoretical and practical notes. Theoretical results can help to recognize the causes and continuing disruption. Moreover, practical results indicate the effect of Nero feedback on the attention deficit, hyperactivity and impulsivity in the ADHD disorder according to the CBCL test. 


\section{Conclusion}

This study attempts to investigate the effect of Nero feedback on attention deficit and hyperactivity. The findings of this study reveal that first, Neurofeedback can reduce $70 \%$ of variance ADHD disorders Neurofeedback have a significant effect on behavioral symptoms, lack of attention and impulsivity; conversely. It seems that it is not successful in reducing symptoms of hyperactivity. Secondly, this method can be used as a supplement or even replace medication for ADHD disorder the last one is Neurofeedback helps brain to regulate and eliminate the defect of function.

\section{Reference}

Achenbach, T. M., \& Rescola, L. A. (2001). Manual for the ASEBA school age: Form \& profiles. Burlington, VT: University of Vermont, Department of Psychiatry.

American Psychiatric Association. (200). Diagostic and Statistical Manual of Mental Disorders (4th ed.). Washington, DC: American Psychiatric Association.

Bukstein, O. (2008). Substance use disorders in adolescents with attention-deficit/Hyperactivity disorder. Adolesc Med state Art Rev, 19, 242-253.

Clarke, A. R., Barry, R. J., McCarthy, R., \& Selikowitz, M. (2001). Age and Sex Effects in the EEG: Differences in two subtypes of attention-deficit/Hyperactivity disorder. Clinical Neurotherapysiology, 112, 815-826. https://doi.org/10.1016/S1388-2457(01)00487-4

Cormier, E. (2008). Attention-Deficit/Hyperactivity Disorder: A review and Update. Journal of Pediatric Nursing, 23, 345-357. https://doi.org/10.1016/j.pedn.2008.01.003

Danforth, J. S., Harvey, E., Ulaszek, W. R., \& Mckee, T. E. (2006). The outcome of group parevt training for families of children with attention deficit Hyperactivity disorder and defiant aggression behavior. Journal of Behavior Therapy and Experimental Psychiatry, 37, 188-205. https://doi.org/10.1016/j.jbtep.2005.05.009

Davidson, M. A. (2008). ADHD in adults: A Review of the literature. Journal of Attention Disorders, 11, 628-641. https://doi.org/10.1177/1087054707310878

Daviss, W. B. (2008). A Review co-morbid depression in pediatric ADHD: Etiology, phenomenology and treatment. Journal of Child and Adolescent Psychopharmacology, 18, 565-571. https://doi.org/10.1089/cap.2008.032

Duffy, F. H. (2000). The state of EEG biofeedback therapy (EEG operant conditioning) in 2000: An editor's opinion. Clinical Electroencephalography, 31(1), v-viii. https://doi.org/10.1177/155005940003100104

Fabino, G. et al. (2008). A comparision of behavior parent training programs for fathers of children with attention-deficit/hyperactivity disorder. Journal of Behavior Therapy, 40(2), 190-204. https://doi.org/10.1016/j.beth.2008.05.002

Gevensleben, H. et al. (2010). Neurofeedback training in children with ADHD: G-month follow-up of a randomized controlled trial. Original Contribution Eur Child Adolesc Psychiatry, 19, 715-724. https://doi.org/10.1007/s00787-010-0109-5

Hillard, B. (2012). Analysis of EEG rhythms using custom-made matlab Application for processing of data collected during Neurofeedback training in ADHD subjects (A Thesis).

Kaiser, D. A., \& Othmer, S. (2000). Effect of neurfeedback on variables of Attention in a large multicenter trial. Journal of Neurotherapy, 4, 25-28. https://doi.org/10.1300/J184v04n01_02

Lazzaro, I., Gordon, E., \& Whitmont, S. (1998). Quantified EEG activity in Adolescent attention-deficit $\begin{array}{llll}\text { hyperactivity } & \text { disorder. } & \text { Clinical } & \text { Electroencephalogry, }\end{array}$ https://doi.org/10.1177/155005949802900111

Lubar, J. F. (2004). Quantitative Electroencephalographic Analysis (QEEG) Databases for Neurotherapy: Description, Validation and Application. Informa Healthcare press. https://doi.org/10.1201/b14464

Napoletano, M. (2016). Neurofeedback: Frequently Asked Questions. Child and Family Counseling Center.

Peyre, H., Speranza, M., Cortese, S., Wohl, M., \& Purper-Ouakil, D. (2015). Do ADHD children with and without child behavior checklist-dysregulation Profile have different clinical characteristics cognitive features and treatment Outcomes? Journal of Attention Disorder, 19(1), 63-71. https://doi.org/10.1177/1087054712452135 
Rostami, R., \& Heshmati, R. (2010). ADHD-Attention Deficit Evaluation Diagnosis and symptoms. Journal of Learning Disabilities, 2(2), 123-158.

Sadock, B. N., \& Sadock, V. A. (2008). Synapses of Psychiatry (9th ed.). Philadelphia: Lippincott the William and Willkins.

Wangler, S. et al. (2011). Neurofeedback in children with ADHD: Specific eventrelated Potential findings of a $\begin{array}{lllll}\text { randomized } & \text { controlled trial. Clinical Neurophysiology, 122, 942-950. }\end{array}$ https://doi.org/10.1016/j.clinph.2010.06.036

White, J. N., Hutchens, T. A., \& Lubar, J. F. (2005). Quantitative EEG Assessment during Neuropsychological Task Performance in adults with Attention Deficit Hyperactivity Disorder. Journal of adult Development, 12(2/3), 113-121. https://doi.org/10.1007/s10804-005-7027-7

Yung, J. (2008). Common comorbidities seen in adolescents with attention-deficit/hyperactivity disorder. Adolesc Med state Art Rev, 19, 216-228.

\section{Copyrights}

Copyright for this article is retained by the author(s), with first publication rights granted to the journal.

This is an open-access article distributed under the terms and conditions of the Creative Commons Attribution license (http://creativecommons.org/licenses/by/4.0/). 